\title{
Empirical Analysis Between Economic Growth and Energy Consumption Based on the Perspective of Industrial Structure
}

\author{
Shu Yehong ${ }^{*}$ and He Yucheng
}

School of Economics and Management, Huazhong Agricultural University, Wuhan, Hubei, 430070, P.R. China

\begin{abstract}
Energy is an important material basis for social and economic development. With the rapid economic development, energy is increasingly becoming an important issue of socio-economic development. As China's "twooriented society" pilots Hunan Province, a major breakthrough occurred in the transformation of economic growth, adjusting the industrial structure and promoting energy conservation and environmental protection, but still faces shortage of energy supply and demand and supply imbalances, impacting on sustainable economic development. This paper introduces the economic growth based on the previous results and summarized the relationship between energy consumption and classification; also introduces the theory of economic growth, industrial structure and related econometric models providing a theoretical basis and methods of analysis for this study. Secondly, through the relevant data collected and selected first from second and third industry time series data of economic growth and energy consumption of the 1990-2013 year of Hunan Province, the paper established econometric model of industrial structure and the relationship between energy consumption and economic growth in the analysis of the results obtained: the secondary industry is the leading cause of long-term increase in energy consumption which in turn is the driving force of the tertiary industry development. Finally, the relevant suggestions are made for industrial restructuring and for ensuring security of energy supply perspective.
\end{abstract}

Keywords: Economic growth, energy consumption, industrial structure, sustainable development.

\section{INTRODUCTION}

Energy is an important material foundation of human social and economic development, where there is a mutual influential relationship between economic growth and energy consumption. In recent years, the rapid development of China's economy has consumed massive energy, making the energy supply situation severe. At the same time, energy consumption structure is not reasonable and energy selfsufficiency rates in some provinces and cities are not moderate.

With the proposal of "two-oriented society" (resourcesaving and environment-friendly society) and the implementation of energy conservation policies, it is imperative to improve the efficiency of energy resources and increase the use of clean energy. CZT (Changsha, Zhuzhou and Xiangtan) urban agglomeration in Hunan Province was approved to be a "two-oriented society" comprehensive pilot reforming area. Therefore, the province needs to work focusing on energy security to ensure the supply of energy for sustainable development of economy and society.

This paper is based on the actual economy development status and energy consumption of Hunan Province, from the perspective of the industrial structure to analyze the relationship between the two. The results provide relevant suggestions for the adjustment of industrial structure

*Address correspondence to this author at the School of Economics and Management, Huazhong Agricultural University, Wuhan, Hubei, 430070, P.R. China; Tel: +86 27 87286896; Fax: +86 2787282973 ;

E-mail: maotou1125@sina.com and energy supply security, finally achieving the coordinated development of economy and energy consumption.

\section{LITERATURE REVIEW}

The research on the relationship between economic growth and energy consumption has always been the focus of attention of the national economists. From the previous existing research at home and abroad, it is evident that majority of the research focused on the study of economic growth and energy consumption, mainly aiming at cointegration theory of economic growth and energy consumption, as well as Granger causality test and the longrun equilibrium relationship. Therefore, this paper reviews and summarizes the relationship between industrial structure, energy consumption and economic growth.

\subsection{Relationship Between Energy Consumption and Economy Growth}

There is a unidirectional causality between economic growth and GDP [1], and it is the rapid development of economy that drives the sharp growth of energy consumption. However, when shorter time series data with intervals are selected, the analysis reaches a different result [2]. In addition, the study also shows that there does not exist any relationship between energy consumption and real income or total employment rate is neither in short term nor in long term [3, 4].

With the rapid development of economy, many scholars have deemed that the traditional factors like capital investment, labor and employment also play an important role in the study of energy consumption and economic 
growth. When labor and capital are taken into account in the relationship, by using co-integration and Granger causality test results, there appears a unidirectional causal relationship between consumption and growth [5]. Moreover, a clear long-term equilibrium relationship is confirmed among GDP, capital investment, labor and energy consumption [6].

\subsection{Relationship Between Industrial Structure and Economy Growth}

The relationship between industrial structure and economy growth is very close as industrial structure has a major influence on the economy growth which in turn has impact, to a certain extent, on the adjustment of the industrial structure.

During the process of economy development in developed countries, the proportion of agriculture reduces to less than $10 \%$. Whether industry is stable or slightly declined, service industry keeps on increasing. Industry share in the national economy appears in an "inverted $U$ " trend [7]. Besides, sustainable and healthy economy growth is due to the influence of dominant industry. Leading industry sector acquired rapid development through advanced technology and also led to the development of related industry [8].

\subsection{Relationship Between Industrial Structure and Energy Consumption}

Early study shows that there is no significant causality between industrial structure and energy consumption, that is to say, the impact of changes in energy consumption by industrial structure is not obvious [9]. The adjustment of industrial structure does not have any influence on the efficiency of energy consumption, while the sub-sector within industry mainly improves the efficiency [10].

However, recent study has proven that reduction of energy consumption intensity is mainly due to a number of factors like enterprise property rights reform, industrial restructuring, changes in energy research spending and energy prices, and so on [11].

\section{THEORY STUDY}

\subsection{Theory of Economic Growth}

Neoclassical economic growth theory suggests that the growth of per capita GDP is due to increased capital per worker by technological change, and thus changes the level of savings and investment. So if the technology stops progressing, growth is over. The theory was first founded by American economist - Solow (1956) and developed through the generations, eventually forming a system which described the economic growth theories.

This model is mainly used to investigate the use of capital K, labor L and knowledge (labor productivity) A to product $\mathrm{Y}$, which aims at studying the inputs and outputs of the production function. So aggregated production function can be expressed as:

$\mathrm{Y}(\mathrm{t})=\mathrm{F}(\mathrm{K}(\mathrm{t}), \mathrm{A}(\mathrm{t}) \mathrm{L}(\mathrm{t}))$
The main point of the neoclassical theory of economic growth is as follows: First, rate of population growth has a decisive role in real GDP growth; Second, technological changes affect the economic growth rate, but the economic growth rate does not have an impact on technological changes; Third, economy maintains a sustainable development because there exists no decrease in wages caused by classical population growth. If the technology stops progressing, the growth also stops; Fourth, if the real interest rate is higher than the target rate of savings, it increases the supply of capital.

\subsection{Industrial Structure Theory}

Industrial structure theory is a major component of the industrial economic theory, and main contents include general rules of industrial restructuring, development of the theory of industrial structure and industrial structure adjustment theory.

As a social division of labor, industry is an economic area between the concept of macro and micro. Constitution of various industries as well as the proportion and coordination of mutual relations are core concepts of the industrial structure. New industries rise gradually, mature industries acquire the dominancy, and traditional industries need to be optimized to adjust the industrial structure. During the whole process of industrial restructuring, the structure becomes rational and sophisticated.

According to the Kuznets rule of industrial restructuring, the proportion of the labor force in the agricultural sector is the last to decline, the industrial sector of the labor force is relatively stable after rising rapidly, while the labor share of the service sector rises with a fast speed.

\section{DESCRIPTION OF MODEL AND DATA}

\subsection{Model Description}

This article is based on the perspective of the industrial structure to study the relationship between economic growth and energy consumption. Therefore, the descriptions of economic model and associated data are needed.

Neoclassical growth model is based on the impact of economic growth, that is, what kind of investment would have a significant impact on growth. If the energy consumption is regarded as a production input, which is included in the production function, the new model of economic growth function is:

$Y=\mathrm{f}(K, L, E, \varepsilon)$

Where, $\mathrm{K}$ represents capital, $\mathrm{L}$ represents labor, E represents energy consumption, $\varepsilon$ is a random error term.

If the form of production function is Cobb-Douglas function, then it can be expressed as:

$Y=A K^{\alpha} L^{\beta} E^{\gamma} \mathcal{E}$

If time dimension is introduced and of both sides of the equation are taken as the logarithm, then the model is:

$\operatorname{In} Y_{t}=\operatorname{In} A_{t}+\alpha \operatorname{In} K_{t}+\beta \operatorname{In} L_{t}+\gamma \operatorname{In} E_{t}+\varepsilon$ 
Both capital and labor inputs are included in the production function as well as energy consumption. The specific relationship between economic growth of three major industries and energy consumption provides a fundamental basis for empirical analysis related to counter measures.

\subsection{Data Sources and Description}

By selecting GDP, labor employment, fixed asset investment and energy consumption regarding three major industries in Hunan Province from 1990 to 2013, the raw data for econometric analysis was obtained.

According to China's division about three industrial structures and combining the actual situation of industry in Hunan province, the classification is made: the agriculture, forestry, sideline, wood, fishing as a primary industry; the industry and construction as the second industry; the remaining of the first and second industries outside as the tertiary industry, including distribution and service industries.

The data this paper used was obtained from the Institute: "Hunan Province Statistical Yearbook", "Energy Statistics Yearbook of Hunan Province", "China Energy Statistical Yearbook", "China Statistical Yearbook" and so on. In order to reduce the error of the data, the data on energy consumption is based on "Energy Statistics Yearbook of Hunan Province," which came out of the data converter, unit energy consumption of 10,000 tons of standard coal; capital investment is the use of fixed-asset investment in various industries, but also through the resulting conversion, the unit incorporates the use of billion; labor input by the end of each year is the number of the industry's graduation data used by the unit million; growth of each variable used in the industry is the industry's GDP each year, the unit incorporates the use of billion.

\section{EMPIRICAL ANALYSIS OF THE INDUSTRIAL STRUCTURE, ENERGY CONSUMPTION AND ECONOMIC GROWTH}

\subsection{Descriptive Statistics}

The GDP of Hunan Province reached 2.45017 trillion yuan in 2013 and the per capita GDP reached 22,719 yuan. Since the reform and opening up, Hunan sustained a rapid economic growth speed at about 10.3 percent average annual.

From industrial point of view, the industrial structure of Hunan gradually became more reasonable, in line with the adjustment of industrial structure Petty - Clark Law and Kuznets law.

The proportions of three industries have changed from 44.6\% 38.4\% 17.0\% (1978) into 47\% 40.4\% 12.6\% (2013). Secondary industry has gradually dominated the proportion of the structure while tertiary industry has increased year by year (as shown in Fig. 1).

Total energy consumption has increased from 38.21 million tons of standard coal (1990) to 175.61 million tons of standard coal (2013), reflecting the social and economic development growth bringing about the energy consumption. At the same time, total energy consumption and the proportion among each industry have changed dramatically (as shown in Fig. 2).

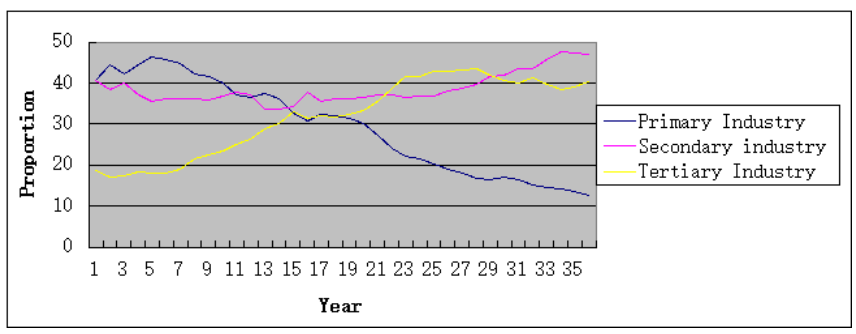

Fig. (1). The proportion of three industries in Hunan province between 1978-2013.

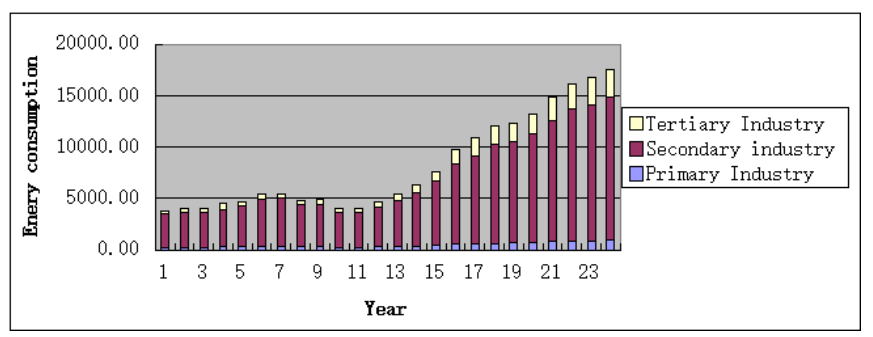

Fig. (2). The total energy consumption of three industries in Hunan province between 1990-2013.

\subsection{Unit Root Test}

In order to determine the stationary phase of time series data, economic variables are needed for unit root test. The DF unit root test firstly determines whether the test model contains a constant term and time trend; secondly, to judge the lag number; and finally, to determine whether time series data is actually stationary.

The unit root test results about three industrial energy consumption, capital investment, labor input and economic growth are shown in Table $\mathbf{1}$.

Table 1. ADF unit root test results of each variable.

\begin{tabular}{|c|c|c|c|c|}
\hline Variable & $\begin{array}{c}\text { ADF Test } \\
\text { Value }\end{array}$ & $\begin{array}{c}\text { Lag } \\
\text { Length }\end{array}$ & $\begin{array}{c}\text { Significance } \\
\text { Level }\end{array}$ & $\begin{array}{c}\text { Critical } \\
\text { Value }\end{array}$ \\
\hline \hline$\Delta^{2} \operatorname{lnY} 1$ & -3.791243 & 3 & $5 \%$ level & -3.673616 \\
\hline LnY2 & -3.376597 & 3 & $10 \%$ level & -3.277364 \\
\hline LnY3 & -3.567058 & 4 & $10 \%$ level & -3.286909 \\
\hline$\Delta^{2} \mathrm{LnK} 1$ & -5.621480 & 0 & $1 \%$ level & -4.498307 \\
\hline$\Delta^{2} \mathrm{LnK} 2$ & -6.093070 & 4 & $1 \%$ level & -4.667883 \\
\hline LnK3 & -4.420928 & 4 & $5 \%$ level & -3.690814 \\
\hline$\Delta \mathrm{LnL} 1$ & -2.865745 & 3 & $10 \%$ level & -2.660551 \\
\hline$\Delta^{2} \mathrm{LnL} 2$ & -4.311241 & 2 & $5 \%$ level & -3.690814 \\
\hline$\Delta \mathrm{LnL} 3$ & -4.050377 & 0 & $5 \%$ level & -3.644963 \\
\hline$\Delta^{2} \mathrm{LnE} 1$ & -6.094242 & 0 & $1 \%$ level & -4.498307 \\
\hline$\Delta^{2} \mathrm{LnE} 2$ & -5.551561 & 0 & $1 \%$ level & -4.498307 \\
\hline$\Delta^{2} \mathrm{LnE} 3$ & -4.129906 & 3 & $5 \%$ level & -3.673616 \\
\hline
\end{tabular}


Table 2. ADF unit root test of residuals e.

\begin{tabular}{|c|c|c|c|c|}
\hline Industry & ADF Test Value & Lag Length & Test Statistic & Significance Level \\
\hline \hline Primary & -3.327898 & 0 & 0.0258 & $5 \%$ level (-3.004861) \\
\hline Secondary & -2.178564 & 0 & 0.0312 & $5 \%$ level (-1.957204) \\
\hline Tertiary & -3.218480 & 4 & 0.0356 & $5 \%$ level (-3.040391) \\
\hline
\end{tabular}

As it is shown in the table, most of the time series data variables are ordinary flat, a few of which are second-order ordinary flat, so it is necessary to make co-integration analysis among economic variables time series.

\subsection{Co-integration Analysis}

In order to verify the existence of co-integration between variables, the EG two-step co-integration model is mainly used. If there exists standardized co-integration vector between economic variables, a long-term co-integration relationship also exists. The main results of co-integration test are shown in Table 2.

Co-integration test results show that there exists standardized co-integration vector between relevant variables, so co-integration equations of three industries are as follows:

$$
\begin{aligned}
& \operatorname{In} Y_{1}=0.151259 \times \operatorname{In} K_{1}-9.836389 \times \operatorname{In} L_{1}-1.094747 \times \operatorname{In} E_{1} \\
& \operatorname{In} Y_{2}=0.615264 \times \operatorname{In} K_{2}+1.184750 \times \operatorname{In} L_{2}+0.368926 \times \operatorname{In} E_{2} \\
& \operatorname{In} Y_{3}=0.368926 \times \operatorname{In} K_{3}+0.044745 \times \operatorname{In} L_{3}-0.108103 \times \operatorname{In} E_{3}
\end{aligned}
$$

Co-integration analysis shows that second industrial economic growth and energy consumption are positively correlated, but the first and tertiary industries have a negative correlation. So, more energy is needed in the second industry for ensuring its development.

\subsection{Causality Test}

Co-integration between economic variables cannot explain the causal relationship between variables, so there is a need to test this causality. The result of Granger causality test based on VAR model is shown in Table 3 .

As can be seen from the table, three major industries all present unidirectional causal relationship between economic growth and energy consumption, indicating that as the total industry growth occurs, energy consumption also increases. Unidirectional causality exists between economic growth and labor input both in primary and tertiary industries, but the directions are opposite. Economic growth and labor input present bidirectional causality in tertiary industries.

\subsection{Impulse Response Analysis}

To further investigate the long-term and dynamic relationship between economic growth and energy consumption in each industry, VAR model has been established for impulse response analysis which tries to draw specifically the relationship between economic growth and energy consumption. The impulse response analysis is shown in Fig. (3), while horizontal axis represents the impact of the role about lag time; vertical axis represents standard deviation of the impact about size and responsiveness future. The solid line represents impulse response function and the dotted line represents two standard confidence bands.

Table 3. The results of Granger test.

\begin{tabular}{|c|c|c|c|c|}
\hline Industry & Null Hypothesis & F Statistic & P Value & Conclusion \\
\hline \hline \multirow{5}{*}{ Primary } & K1 not Cause Y1 & 2.06783 & 0.1589 & accept \\
\cline { 2 - 5 } & Y1 not Cause K1 & 0.60809 & 0.5565 & accept \\
\cline { 2 - 5 } & L1 not Cause Y1 & 2.86598 & 0.0863 & reject \\
\cline { 2 - 5 } & Y1 not Cause L1 & 0.35247 & 0.7083 & accept \\
\cline { 2 - 5 } & E1 not Cause Y1 & 3.59059 & 0.0515 & reject \\
\cline { 2 - 5 } & Y1 not Cause E1 & 0.10532 & 0.9007 & accept \\
\hline \multirow{5}{*}{ Secondary } & K2 not Cause Y2 & 1.47837 & 0.2575 & accept \\
\cline { 2 - 5 } & Y2 not Cause K2 & 2.53264 & 0.1108 & accept \\
\cline { 2 - 5 } & L2 not Cause Y2 & 6.70124 & 0.0077 & reject \\
\cline { 2 - 5 } & Y2 not Cause L2 & 3.69578 & 0.0479 & reject \\
\cline { 2 - 5 } & E2 not Cause Y2 & 4.20522 & 0.0341 & reject \\
\cline { 2 - 5 } & Y2 not Cause E2 & 1.63949 & 0.2251 & accept \\
\hline \multirow{5}{*}{ Tertiary } & K3 not Cause Y3 & 2.63881 & 0.1022 & accept \\
\cline { 2 - 5 } & Y3 not Cause K3 & 0.63205 & 0.5443 & accept \\
\cline { 2 - 5 } & L3 not Cause Y3 & 1.95175 & 0.1744 & accept \\
\cline { 2 - 5 } & Y3 not Cause L3 & 2.74041 & 0.0947 & reject \\
\cline { 2 - 5 } & E3 not Cause Y3 & 12.7807 & 0.0005 & reject \\
\cline { 2 - 5 } & Y3 not Cause E3 & 1.70350 & 0.2134 & accept \\
\hline
\end{tabular}

From the perspective of the impulse response process, the conclusion can be drawn that suggests that increasing economic development boosts energy consumption, but when a certain period is reached, the impact of energy consumption on economic growth stays in a stable state; economic growth increases energy consumption in shortterm, however, the impact from a certain period starts to become stable.

\section{CONCLUSION}

So the relationship between economic growth and energy consumption is actually a mutual influence, especially in the industry which requires enormous energy for consumption. In the period of accelerated industrialization and urbanization, ensuring energy security is an important 
Response of Y1 to E1
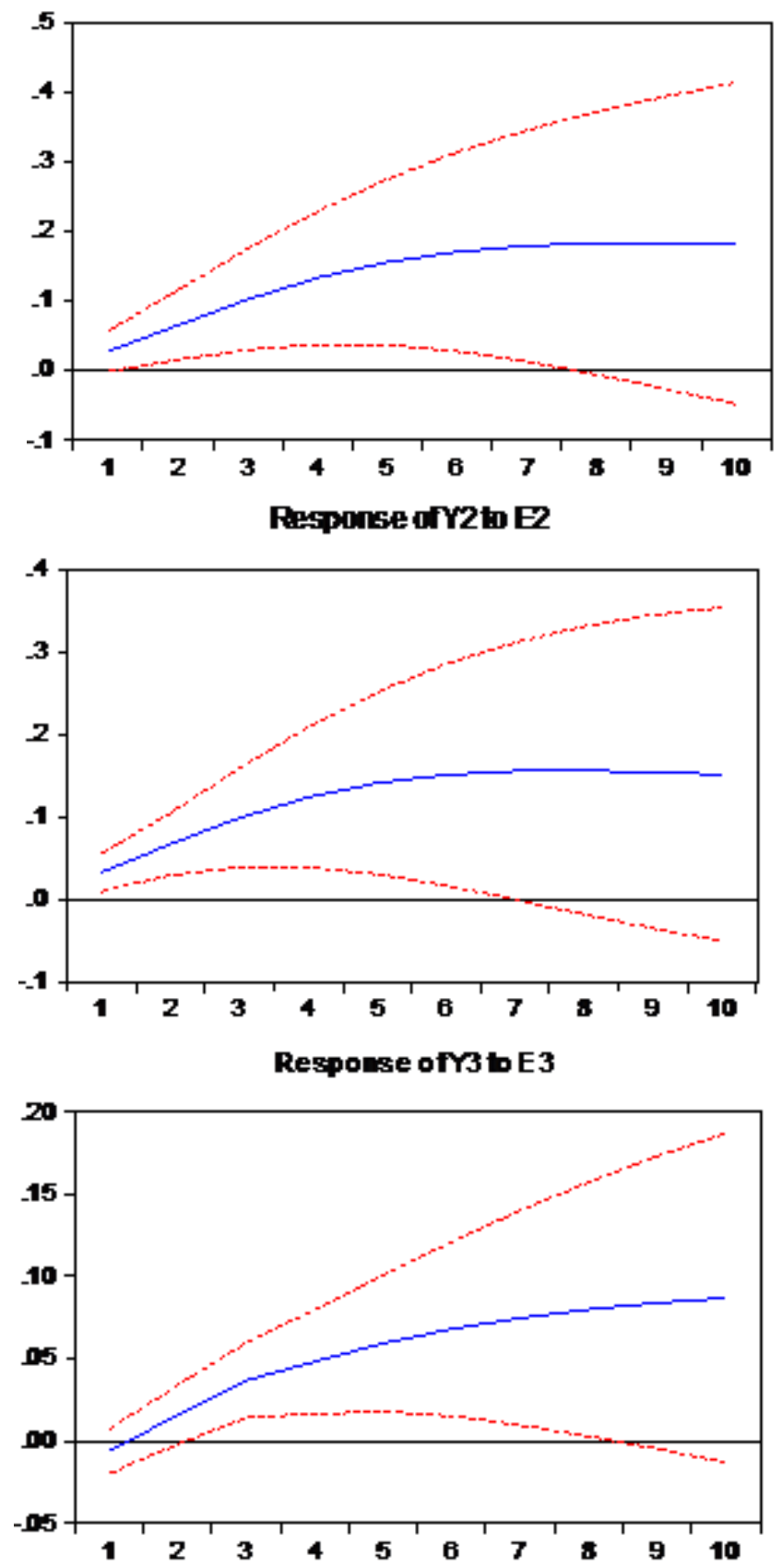

Recponse of E1to Y1
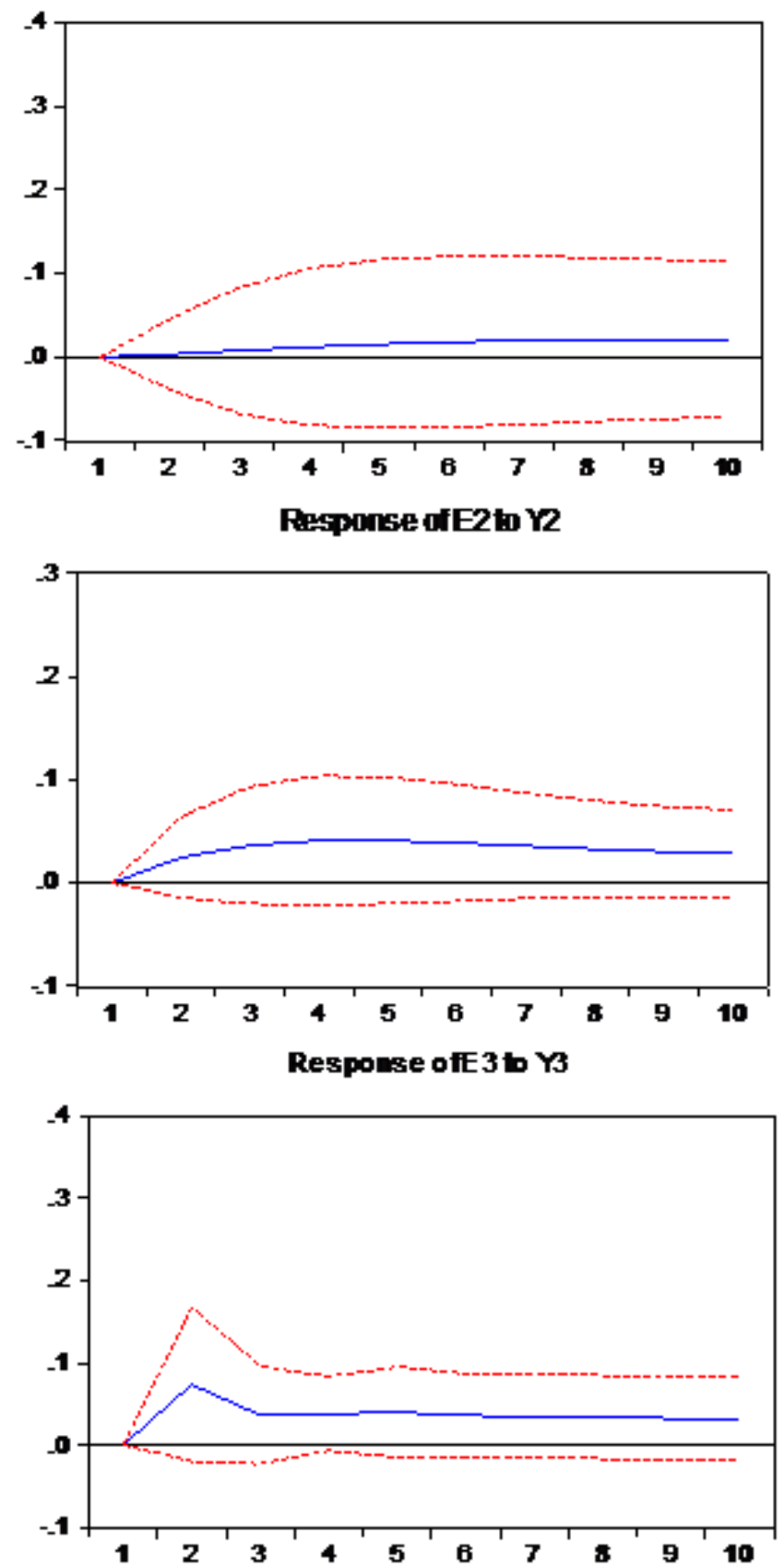

Fig. (3). The impulse response of economic growth and energy consumption.

measure to promote economic growth and industrial transformation or upgrading.

Positively, to develop renewable energy is an important measure to ensure security of energy supply and to promote sustainable economic development. As a new type of energy, nuclear power has the feature of less pollution and enormous energy. In addition, the development of biomass energy supply has critical significance for supply security. Compared to traditional energy, the use of biomass not only seldom makes pollution for the environment, but also improves the efficiency of energy generation. Facing the situation that energy consumption structure is irrational and environment pollution becomes serious, therefore the development of renewable energy is the only way to ensure security.

On the other hand, some useful measures may contribute to expand the energy-saving work. For instance, the fusion of economy cycle and high-tech industry must be strengthened to improve energy efficiency and economic benefits. For high energy-consuming industries, such as petrochemical, textile and paper industries, economic, administrative and legal means must be considered along with related policies to reduce energy consumption. Finally, low-carbon and conservative lifestyles must be promoted which rely on technological progress towards the saving pattern of urbanization. 


\section{CONFLICT OF INTEREST}

The authors confirm that this article content has no conflict of interest.

\section{ACKNOWLEDGEMENTS}

Declared none.

\section{REFERENCES}

[1] Kraft, J.; Kraft, A. On the relationship between energy and GNP. J. Energy Dev., 1978, 3, 401-403.

[2] Akarca, A.T.; Long, A.T. On the relationship between energy and GNP: a re-examination. J. Energy Dev., 1980, 5, 326-331.

[3] Eeol, U.E.; Yu S.H. Spectral analysis of the relationship between energy consumption, employment, and business cycles. Resour. Ener., 1990, 11, 395-412.
[4] Granger, C.W.J.; Terasvirta, T. Modeling Non-Liner Economic Relationships. Oxford University Press, Oxford, 1993.

[5] Stern, D.I. Energy use and economic growth in the USA: a multivariate approach. Energ. Econ., 1993, 15, 137-150.

[6] Stern, D.I. A multivariate co-investigation analysis of the role of energy in the US macro-economy. Energ. Econ., 2000, 22, 267283.

[7] Balat, K.M. Energy consumption and economic growth in Turkey during the past two decades. Energ. Policy., 2008, 1, 118-127.

[8] Paul, R. A model of innovation, technology transfer, and the world distribution of income. J. Polit. Econ., 1979, 87(2), 253-266.

[9] Hwang, D.B.K.; Gum, B. The causal relationship between energy and GNP: the case of Taiwan. J. Energ. Dev., 1992, 12, 219-226.

[10] Xiang, Z.Z. Why did the energy intensity fall in China's industrial sector in the 1990s In: East-West Center Working Papers, 2003.

[11] Mahadevan, R.; Asafu-Adjaye, J. Energy consumption, economic growth and prices: a reassessment using panel VECM for developed and developing countries. Energ. Policy., 2007, 4, 24812490.

(C) Yehong and Yucheng; Licensee Bentham Open

This is an open access article licensed under the terms of the (https://creativecommons.org/licenses/by/4.0/legalcode), which permits unrestricted, noncommercial use, distribution and reproduction in any medium, provided the work is properly cited. 